\title{
Mouse Models of Human Cancer
}

National Cancer Institute

\section{Source}

National Cancer Institute. Mouse Models of Human Cancer. NCI Thesaurus. Code C19260.

A neoplastic disease of a mouse with clinical features sufficiently similar to those of a human cancer to serve as a test system. 